\title{
Family caregivers of people who have intellectual/ developmental disabilities and asthma: Caregiver knowledge of asthma self-management concepts-A pilot study
}

\author{
Steven R. Erickson (i) | Sophia Juncaj | Charlotte Buckley
}

University of Michigan College of Pharmacy, Ann Arbor, Michigan

Correspondence

Steven R. Erickson, University of Michigan

College of Pharmacy, Ann Arbor, MI.

Email: serick@med.umich.edu

\section{Accessible Summary}

- Asthma is a problem for many people.

- Some people need help with their medicines for asthma.

- People who help with medicines should know how medicines work and how they are used.

- This study found that many helpers need more education about asthma medicines.

\section{Abstract}

Background: People who have an intellectual or developmental disability (IDD) and asthma are at greater risk of poor health outcomes. They often require assistance from caregivers when managing their medicines. The objective of this pilot study was to assess the level of understanding of asthma self-management concepts of family caregivers who provide assistance to people who IDD and asthma. Results will inform future needs assessment and intervention studies.

Materials and Methods: Nineteen caregivers of people who have asthma and IDD completed a mailed survey. The survey included scales to measure asthma self-management concepts, inhaler technique knowledge, medication adherence and control of asthma. The caregivers were instructed to complete most of the scales with reference to the person with IDD.

Results: Most caregivers had acceptable health literacy, but had low scores on the asthma self-management and inhaler technique tests. The most frequently cited barriers to controlling asthma were inadequate caregiver and patient education about the illness as well as knowing and avoiding asthma triggers. The most frequently cited barriers to medication management were knowing inhaler technique, knowledge of medication and forgetting to use medication. Asthma was controlled in $63.2 \%$ of patients, while almost $75 \%$ of patients were considered nonadherent to controller therapy.

Conclusions: Most caregivers had inadequate understanding of asthma selfmanagement as well as inhaler technique despite having high health literacy. Improving caregiver and patient knowledge and skills may lead to better asthma control.

\section{KEYWORDS}

asthma, caregivers, developmental intellectual disability, medication, self-management, control 


\section{1 | INTRODUCTION}

While asthma appears to be at least as prevalent in people with IDD as compared to the general population, about $8 \%$ of the population (Morin, Mérineau-Côté, Ouellette-Kuntz, Tassé, \& Kerr, 2012), other studies have documented a higher prevalence of up to $12 \%$ (Davis, 2016). People with IDD and asthma are at greater risk of emergency room use, hospitalisation and mortality than the general population (Gale, Naqvi, \& Russ, 2009; Kerins, Petrovic, Bruder, \& Gruman, 2008; Reichard, Stolzle, \& Fox, 2011; Schieve et al., 2012). People with IDD face challenges related to self-management that often require the assistance of caregivers. In essence, self-management of chronic disease becomes supported self-management, whereby the caregiver is involved to the extent necessary to assist the care-recipient manage their asthma therapy. The person with IDD and the support network of caregivers must work together to control illness. Successful management of chronic illness requires an informed and competent team. Factors that should be taken into consideration for self-management to be successful would include considering the patient's level of functioning as well as the environment in which the person lives. Interventions intended to promote self-management of health should be targeted at both the patient, the support network of caregivers and the supportive environments in which the patient interacts such as the health system, supports agencies and extended networks of family and friends (Marks \& Sisirak,2013). Research has demonstrated that disease-management interventions which include self-management aspects produce positive impact on health outcomes for people with IDD. For example, a community-based health intervention developed using peers and diabetes educators was successful in increasing physical activity and changing eating behaviour, leading to improved clinical outcomes in a group of adults with mild IDD (Bazzano et al., 2009). Another study of adults with diabetes and IDD found that most participants were able to participate in self-management activities, although with assistance from caregivers. Support from others was important in this process (Hale, Trip, Whitehead, \& Conder, 2011). A small study of patients with mild intellectual disability found that the participants had good understanding of the importance of managing their asthma medication regimen (Davis, 2016).

In patients who have asthma but do not have IDD, asthma is not well controlled. Population-based studies finding that between 55\% and 59\% of people with asthma are controlled based on assessment of symptoms using standardised instruments (Chapman, Boulet, Rea, \& Franssen, 2008; Peters et al., 2007; Schatz et al., 2007). There are no studies of the level of control of asthma for patients with IDD and asthma.

\section{2 | REVIEW OF THE LITERATURE}

Caregivers have an important role in ensuring safe and effective use of medications by people with IDD. Caregivers encompass a wide range of people who provide support for daily functional activities for the person with IDD. Caregivers include family, friends and employed support personnel hired by the person with IDD or provided by a supports agency. A recent survey of caregivers of adults who have IDD identified their level of involvement in medication management for people with IDD, with over $70 \%$ of respondents indicating that they obtained medication from pharmacies, reminded the person with IDD to take medication, and physically handed the medication to the person with IDD when it was time to take a dose (Erickson \& LeRoy, 2015). In regard to asthma specifically, an excellent qualitative study provides evidence of the needs that employed caregivers, or direct support professionals (DSPs) have in regard to assisting in the overall asthma management of their clients who have IDD (Davis et al., 2015). Davis et al found that DSPs are integral to the support of people with IDD and asthma, and that DSPs feel more training is needed to be able to properly fulfil their role in supporting the health needs of the person with IDD. Specifically, training on appropriate inhaler technique as well as provision of appropriate decision supports tools to judge when reliever medications are needed are examples of important findings. The same researchers also provided evidence that people with IDD and asthma often do not perform inhaler technique appropriately (Davis et al., 2016).

Successful management of asthma requires knowledge of asthma triggers and treatment, correct inhaler technique, understanding an asthma action plan, understanding the use of a peak flow metre, accurate interpretation of breathing symptoms, use of spacer devices and adherence to therapy. Appropriate management leads to maintained or improved control of asthma, which improves quality of life and reduces morbidity and mortality associated with the illness. Identification of problems associated with medication management may guide interventions to further develop self-management interventions specific to the needs of unique populations such as patients with IDD. Little is known about the overall level of control of asthma in patient with IDD, or of the ability of caregivers who are involved in medication management to adequately manage the medications used to control asthma.

\section{3 | RESEARCH QUESTION/HYPOTHESES}

The goal of this pilot study was to assess the understanding of asthma self-management concepts of caregivers who provide medication management assistance to people who have intellectual or developmental disabilities and asthma. Secondary objectives were to measure asthma control and medication adherence of adult patients with IDD and asthma. It is anticipated that findings from this study will be used to develop a larger, multicenter study that incorporates assessment and intervention.

\section{MATERIALS AND METHODS}

\section{1 | Subjects and survey method}

The subject of this study was the caregiver of an adult (age 18 years or older) patient with IDD and asthma. A large health system located in a Midwestern state (United States) maintains an electronic data warehouse. Using the query tool DataDirect, 
investigators are able to search for and identify patients with various demographic and medical characteristics once a study has approval by the human investigations committee. To create a sample of caregivers of people with IDD, the investigators followed the logic of first identifying patients with IDD and asthma who were seen by clinicians in the adult general medicine or family medicine clinics within the health system, which would lead to the caregiver who assists in managing medication. To be included in the study, the caregiver must have been age 18 years or older. Caregivers were identified by searching the health system's data warehouse for patients who have asthma, were age 18 years and older and who had a diagnosis related to IDD. The IDD-related conditions identified for this study were based on ICD9 classifications and included Mental Retardation (317, 318, and 319), Down syndrome, Foetal Alcohol Syndrome, Autism Spectrum Disorder, Other Genetic Abnormalities, Cerebral Palsy and Developmental Delay. The diagnosis associated with IDD must have been documented at least once in any procedure, visit or hospitalisation/emergent care event from 2012 to 2014 . Once the IDD sample was constructed, it was further searched for patients with asthma. The diagnosis of asthma must have been documented at least two times in the electronic health records, from 2013 to the end of 2014. The requirement of being documented at least two times was an attempt to increase the likelihood that the patient had a confirmed diagnosis of asthma. The final list of patients with IDD and asthma underwent a validation check by the investigators reviewing the electronic medical record. The query initially identified 453 patients with IDD diagnosis. When further filtered by asthma diagnosis and chart review to confirm both IDD and asthma diagnosis, 239 subjects were identified for the study sample. Addresses were obtained from the medical record and survey packets sent to the address of the patient, but labelled for the caregiver. The covering letter in the survey packet was written to indicate that the study was focused on the caregiver who assists in managing asthma medicine. Three mailings were made, including the initial survey packet, a reminder postcard sent 2 weeks later, followed by a second survey packet 4 weeks after the initial mailing to subjects who had not yet responded. A total of five patients or caregivers contacted the investigator to opt out of the study and 12 packets were not deliverable and returned. Of the remaining 222 potential subjects, 18 returned survey packets, for a response rate of $8.1 \%$. Therefore, due to the small sample size, this study is considered to be a pilot study, in which we are identifying the most salient and potential caregiver and patient factors that may be associated with asthma self-management concepts as well as control for patients with IDD and asthma, keeping in mind that caregivers are an integral part of successful medication management. The study was approved by the Institutional Review Board.

The study survey consists of a number of questionnaires included to measure specific concepts. The Asthma Self-Management Questionnaire, the health literacy scale and the inhaler technique questionnaire are direct measures of the caregiver's understanding and health literacy. The questions about the patient's use of spacer devices, peak flow metres and having an asthma action plan are asked of the caregiver with the notion that they have direct knowledge of the use or the presence of these devices or asthma action plan. The questionnaires assessing asthma medication adherence and asthma control were originally developed to be self-administered by the patient. For this study, the caregiver was instructed to consider the care-recipient when answering each question. As for medication adherence, we feel that the caregiver is knowledgeable to factors related to the medication-taking behaviour of the care-recipient, as they are often very involved in overseeing medication management. We did not conduct a validation of this technique prior to initiating the study. There is an opportunity for misrepresentation of the findings when someone other than the patient completes the questionnaire. In pre-test, we found that patients with IDD had difficulty completing the instrument. We elected to utilise the caregiver to function as the surrogate responder for the items. Literature, primarily in cancer care, demonstrates that caregiver and patient assessment of symptoms such as pain and fatigue are at least moderately correlated (Desbiens \& Mueller-Rizner, 2000; McPherson, Wilson, Lobchuk, \& Brajtman, 2008; Poort et al., 2016). We expected that the caregiver completing the survey would have a close enough relationship with the patient to be able to complete the questions with a fair representation of the answer. This study, being a pilot study, will provide initial evidence as to the feasibility of being able to utilise the caregiver as a survey surrogate. Future research may be conducted to further determine the validity of the process.

\section{2 | Data}

\subsubsection{Characteristic of the caregiver and the person with IDD}

Characteristics of the caregiver included age, gender, race, level of formal education, whether they ever received training in asthma management or medication management, and personal history of medication use. To measure functional independence of the person with IDD, the caregiver was asked how many hours, on average, did the person require support per day. A separate question assessed the level of patient independence in self-managing asthma medication.

\subsection{2 | Caregiver asthma self- management knowledge}

It is assumed that in order for caregivers to provide care, they must have adequate knowledge and understanding of the illnesses and related treatments that the care-recipient experiences. We therefore used the Asthma Self-Management Questionnaire to assess caregiver understanding of key components of successful asthma self-management It consists of sixteen multiple choice questions that assess medication knowledge, trigger avoidance, use of peak flow metres and asthma disease knowledge. The instrument has good psychometric properties and corresponds to changes in clinical asthma status over time (Mancuso, Sayles, \& Allegrante, 2009). 


\subsection{3 | Caregiver inhaler technique questionnaire}

A standardised checklist of inhaler technique was used to assess caregiver knowledge of inhaler technique. The checklist was developed and validated as a tool to screen patients for incorrect inhaler technique (Erickson, Horton, \& Kirking, 1998).

\subsubsection{Health literacy of the caregiver}

A three-item brief health literacy screening scale developed by Chew, Bradley, \& Boyko (2004) was used to assess health literacy of the caregivers. The original scale instructs subjects to respond on a 5-point Likert scale to three items: "How often do you have problems learning about your medical condition because of difficulty understanding written information?" (Responses range from all of the time to none of the time); "How confident are you filling out medical forms by yourself?" (Responses range from extremely to not at all); and "How often do you have someone help you read hospital materials?" (Responses range from all of the time to none of the time). The version of the instrument which modified the original third question to "How often do you have someone help you read instructions, pamphlets, or other written materials from your doctor or pharmacy?" was used for this study (Morris, MacLean, Chew, \& Littenberg, 2006). After reversescoring the item addressing confidence with forms, responses to the three items are summed; scores range between 3 and 15, with higher scores indicating higher health literacy.

\subsection{5 | Patient medication adherence}

The Medication Adherence Report Scale for Asthma (MARS-A) was used as a self-report measure of adherence to each of the subject's controller medications (Cohen et al., 2009). The MARS-A is a tenitem questionnaire. Medication use is rated on a 5-point Likert scale with higher scores indicating better adherence. The MARS-A has been tested and has strong psychometric properties. The caregiver completed the MARS-A with the focus on the patient medicationtaking behaviour. A MARS-A score of 4.5 or higher was defined as good adherence.

\subsection{6 | Patient use of spacer device/The presence of an asthma action plan}

A question was asked whether or not the patient uses a spacer device to assist in the drug delivery process for metered dose inhalers. The caregiver was asked whether the patient had an asthma action plan produced by a healthcare provider.

\subsection{7 | Asthma control}

The Asthma Control Questionnaire (ACQ) was used to measure the level of control of asthma (Juniper, O'Byrne, Guyatt, Ferrie, \& King, 1999). The ACQ was developed as a way to determine the degree of asthma control using information from the patient about symptoms, medication utilisation and pulmonary function testing. The symptoms-only version of the ACQ was used for this study, as it does not include pulmonary function test information or the question on medication utilisation (Juniper, Svensson, Mörk, \& Ståhl, 2005). It includes five items to assess the patient's limitations due to asthma in performing activities of daily living. Generally, asthma is considered controlled with ACQ scores below 1.5 (Juniper, Bousquet, Abetz, \& Bateman, 2006). This value provides a positive predictive value of 0.84 and negative predictive value of 0.63 . A more sensitive cut-point described as being more useful for clinical assessment is 0.75 . This value provides a negative predictive value of 0.81 and positive predictive value of 0.72 . These two values were used for this study to differentiate subjects as controlled versus not controlled. The caregiver completed the ACQ with the focus on the patient's symptoms.

\subsection{8 | Barriers to medication management and asthma control}

A qualitative assessment of barriers was conducted using openended questions, asking the caregiver to describe barriers associated with using asthma medications safely and effectively, as well as to describe barriers to controlling asthma.

\section{3 | Data analysis}

Description of the sample was conducted using means with standard deviation for continuous variables and frequencies with percentage for categorical variables. Because of the small number of respondents, further comparative analyses between caregiver and patient characteristics and asthma self-management scale scores were not conducted. Qualitative data described by the respondents about barriers to obtaining and used asthma medication were analysed using a thematic content analysis. This method was performed to identify issues encountered by caregivers around asthma management and medication management was coded. The analysis was performed inductively where the themes emerged from the data. The passages coded were ordered by thematic similarity or relationship into a project codebook and combined to reduce data to conceptualised themes. Finally, through a thorough process of analysis and comparison back to the original transcripts, data were grouped into major themes. The codebooks obtained by each reviewer were discussed at two different times and consensus on interpretation of the content was achieved. Final themes were then counted to determine how many times they were mentioned by respondents.

\section{5 | RESULTS}

A total of 19 caregivers completed the survey. Characteristics of the respondents are presented in Table 1. All caregivers were family members of the person with IDD, had a mean age of 53 years, were 
TABLE 1 Characteristics of the caregiver $\left(n=19\right.$ respondents $\left.{ }^{\mathrm{a}}\right)$

\begin{tabular}{|c|c|}
\hline Characteristic & $\begin{array}{l}\text { Frequency (\%) or } \\
\text { Mean (SD) }\end{array}$ \\
\hline Age & $\begin{array}{l}53.8(12.1) \\
\text { Range } 28 \text { to } 70\end{array}$ \\
\hline Gender-Female & $16(88.9)$ \\
\hline \multicolumn{2}{|l|}{ Relationship to the patient } \\
\hline Parent or sibling & $19(100)$ \\
\hline \multicolumn{2}{|l|}{ Education } \\
\hline Did not graduate high school & $1(5.6)$ \\
\hline High school graduate or GED & $5(27.8)$ \\
\hline Some college or more & $12(66.7)$ \\
\hline \multicolumn{2}{|l|}{ Education in health care } \\
\hline Yes & $6(33.3)$ \\
\hline \multicolumn{2}{|l|}{ Participate in medication administration training } \\
\hline Yes & $5(27.8)$ \\
\hline \multicolumn{2}{|l|}{ Health literacy } \\
\hline $\begin{array}{l}\text { Confidence in filling medical forms by } \\
\text { self-Higher Health Literacy }\end{array}$ & $16(84.2)$ \\
\hline $\begin{array}{l}\text { Need help reading hospital materials-Higher } \\
\text { Health Literacy }\end{array}$ & $15(78.9)$ \\
\hline $\begin{array}{l}\text { Problems learning about medical conditions } \\
\text { because of difficulty understanding written } \\
\text { information-Higher Health Literacy }\end{array}$ & $16(84.2)$ \\
\hline Caregiver Asthma Self-Management & $56.6(22.0)$ \\
\hline $\begin{array}{l}\text { Questionnaire score. Higher score = better } \\
\text { self-management knowledge }\end{array}$ & $\begin{array}{l}\text { Range } 12.5 \text { to } \\
81.3\end{array}$ \\
\hline Caregiver inhaler technique knowledge score & $6.5(1.6)$ \\
\hline Higher score (10 maximum) = better technique & Range 4 to 9 \\
\hline
\end{tabular}

${ }^{a}$ One respondent did not provide answers to questions assessing caregiver age, gender, or education.

female and had at least some college training as a measure of formal education. One-third had education in a health-related field. Most respondents were classified as having acceptable health literacy. The person with IDD required supervision, on average, over $18 \mathrm{hr}$ per day. Refer to Table 2 for data on the person with IDD. Almost two-thirds of the people with IDD depended completely on the caregiver to assist them to manage their asthma medication therapy, with approximately another one-third requiring some assistance. Assessment of adherence to asthma medication, assessed by the MARS-A scale and using the predetermined cut-point in the score, found that almost $75 \%$ of the patients were classified in the lower adherence. Just over half of the patients had an asthma action plan, and only twelve per cent used a peak flow metre in their overall management of asthma.

The Asthma Control Questionnaire scores ranged from 0 to 4.2 (lower values indicate better control), with a mean of $1.2( \pm 1.2)$. The number of patients considered to have asthma that was controlled was $12(63.2 \%)$ using the score threshold of 1.5 . If the more clinically sensitive score of 0.75 was used as the cut-point, a total of 10 (52.6\%) patients were considered controlled.
TAB LE 2 Characteristics of the patient with asthma and intellectual/developmental disability $(n=19)$

\begin{tabular}{|lcc|}
\hline $\begin{array}{l}\text { Characteristic } \\
\text { Age }\end{array}$ & Frequency (\%) & \multicolumn{1}{c}{$\begin{array}{c}\text { Mean (SD) } \\
\text { Range } 19 \text { to } 65\end{array}$} \\
\hline $\begin{array}{l}\text { Gender-Female } \\
\text { Intellectual/developmental disability }\end{array}$ & \\
\hline $\begin{array}{l}\text { Cerebral palsy } \\
\text { Developmental delay }\end{array}$ & $8(42.1)$ & \\
\hline $\begin{array}{l}\text { Autism spectrum } \\
\text { disorder }\end{array}$ & $4(21.1)$ & \\
\hline $\begin{array}{l}\text { Down syndrome } \\
\text { Number of hours per } \\
\text { day the patient } \\
\text { requires supervision }\end{array}$ & $1(5.3)$ & Range 2 to 24 \\
\hline
\end{tabular}

Extent to which patient manages asthma medication themselves

$\begin{array}{lc}\text { Completely } & 1(5.3) \\ \begin{array}{l}\text { Needs some } \\ \text { assistance }\end{array} & 6(31.6) \\ \text { Depends on caregiver } & 12(63.2)\end{array}$

MARS-A Score (asthma

$3.65(1.0)$

medication adherence

scale)

Higher score $=$ better

Range 1.5 to 5

adherence

Asthma medication adherence scale score dichotomised ${ }^{a}$

\begin{tabular}{lc} 
Higher adherence & $5(27.8)$ \\
\hline Lower adherence & $13(72.2)$ \\
$\begin{array}{l}\text { Does the patient have } \\
\text { an asthma action } \\
\text { plan?-Yes }\end{array}$ & $10(55.6)$
\end{tabular}

Does the patient use a 2 (12.5) peak flow metre ${ }^{a}$
Asthma control
$1.2(1.2)$ questionnaire score

Higher score = lower asthma control

Range 0 to 4.2

Asthma Control Questionnaire Score Dichotomised (1.5 cut-point)

$\begin{array}{lr}\text { Better asthma control } & 12(63.2) \\ \begin{array}{l}\text { Poorer asthma } \\ \text { control }\end{array} & 7(36.8) \\ \end{array}$

Asthma control questionnaire score dichotomised ( 0.75 cut-point)

Better asthma control $10(52.6)$

Poorer asthma 9 (47.4)

control

${ }^{a}$ Not all subjects provided answers to these questions.

Caregiver scores on the Asthma Self-Management Questionnaire ranged from 12.5 to 81.3 , with a mean of 56.6 $( \pm 22)$. The highest score achievable is 100 , indicating the highest level of understanding of asthma management. Examining the correct responses for each question within the ASMQ, the areas of greatest knowledge deficit include interpretation of prescription 
TABLE 3 Asthma self-management questionnaire-individual item results $(n=19)$

\begin{tabular}{|c|c|}
\hline $\begin{array}{l}\text { Individual ASMQ Questions (... with } \\
\text { correct response) }\end{array}$ & $\begin{array}{l}\text { Number and percent } \\
\text { correct response }\end{array}$ \\
\hline $\begin{array}{l}\text { A main method to prevent asthma } \\
\text { flare-ups is to ... get a flu vaccine }\end{array}$ & $5(26.3)$ \\
\hline $\begin{array}{l}\text { Taking the prescribed two puffs of you } \\
\text { inhaler two times a day ... is not the same } \\
\text { as any other regimen }\end{array}$ & $8(42.1)$ \\
\hline $\begin{array}{l}\text { If you are not having asthma symptoms ... } \\
\text { you should still avoid triggers }\end{array}$ & 14 (73.7) \\
\hline $\begin{array}{l}\text { Maintenance medicines ... help prevent } \\
\text { future symptoms }\end{array}$ & 15 (78.9) \\
\hline $\begin{array}{l}\text { The correct way to use peak flow metre is } \\
\text { to ... take a deep breath then blow into } \\
\text { the mouthpiece as fast as you can }\end{array}$ & 2 (10.5) \\
\hline $\begin{array}{l}\text { Rescue medicines ... should not be taken } \\
\text { more than three or four times a day }\end{array}$ & $16(84.2)$ \\
\hline $\begin{array}{l}\text { When using your inhaler, you should ... } \\
\text { inhale slowly }\end{array}$ & $9(47.4)$ \\
\hline $\begin{array}{l}\text { After you have used your inhaler, you } \\
\text { should ... hold your breath for several } \\
\text { seconds }\end{array}$ & $12(63.2)$ \\
\hline $\begin{array}{l}\text { If you are having symptoms and don't know } \\
\text { why, the first thing you should do is ... } \\
\text { change your immediate environment }\end{array}$ & 5 (26.3) \\
\hline $\begin{array}{l}\text { Taking more rescue medications than } \\
\text { prescribed ... may mean you need more } \\
\text { maintenance medicine }\end{array}$ & $12(63.2)$ \\
\hline $\begin{array}{l}\text { The benefit of using a peak flow metre } \\
\text { every day is ... you can detect small } \\
\text { changes in lung function even before } \\
\text { symptoms start }\end{array}$ & $11(57.9)$ \\
\hline $\begin{array}{l}\text { For people with asthma, exercise ... can } \\
\text { help improve breathing capacity }\end{array}$ & 8 (42.1) \\
\hline $\begin{array}{l}\text { Asthma can be cured by ... there is no } \\
\text { known cure for asthma }\end{array}$ & $16(84.2)$ \\
\hline $\begin{array}{l}\text { Asthma flare-ups ... can occur when several } \\
\text { minor triggers come together }\end{array}$ & $9(47.4)$ \\
\hline $\begin{array}{l}\text { If you are prescribed a seven-day course of } \\
\text { steroid pills ... you should finish the } \\
\text { prescription even if you feel better after } \\
\text { several doses }\end{array}$ & $16(84.2)$ \\
\hline $\begin{array}{l}\text { Which of the following can help control } \\
\text { asthma? ... Reducing the stress level, } \\
\text { drinking plenty of water to stay hydrated, } \\
\text { and avoiding foods with sulphites, such as } \\
\text { dry fruits and wine }\end{array}$ & 14 (73.7) \\
\hline
\end{tabular}

TABLE 4 Themes present in the qualitative assessment

\begin{tabular}{|ll|}
\hline Barriers to controlling asthma & $\begin{array}{l}\text { \% of caregivers } \\
(n=11)\end{array}$ \\
\hline $\begin{array}{l}\text { Education of patient and/or caregiver } \\
\text { Asthma triggers and symptoms }\end{array}$ & 36.4 \\
\hline $\begin{array}{l}\text { Lack of follow-up/care coordination } \\
\text { Clinician familiarity/ability to work with } \\
\text { patients with IDD }\end{array}$ & 18.2 \\
\hline $\begin{array}{l}\text { Barriers to using asthma medication safely } \\
\text { and effectively }\end{array}$ & $\begin{array}{l}\% \text { of caregivers } \\
(n=13)\end{array}$ \\
\hline $\begin{array}{l}\text { Knowing and performing correct inhaler } \\
\text { technique }\end{array}$ & 46.2 \\
\hline $\begin{array}{l}\text { Education about medications for caregiver/ } \\
\text { patient }\end{array}$ & 38.5 \\
\hline $\begin{array}{l}\text { Forgetfulness } \\
\text { Communication between patient and }\end{array}$ & 15.4 \\
\hline caregiver & 7.7 \\
\hline $\begin{array}{l}\text { Lack of follow-up/care coordination } \\
\text { Cost of medication }\end{array}$ & 7.7 \\
\hline
\end{tabular}

from 4 to 9, with 10 being the highest possible score indicating the greatest understanding of inhaler technique.

Responses to the open-ended questions regarding barriers to asthma control and barriers to asthma medication utilisation were summarised into specific themes. Refer to Table 4 for a summary of the responses. Eleven respondents provided their thoughts about barriers to asthma control. The most common barrier to controlling asthma was inadequate education of the caregiver and patient about the illness and treatment. The next most common theme mentioned was knowing and avoiding asthma triggers. Concerning medical care of asthma, lack of consistent follow-up and coordination of care for asthma was the third barrier. The final theme was familiarity and ability of the clinician to work with patients with IDD.

Thirteen respondents provided information regarding barriers to asthma medication management. The most frequently cited barrier was struggling to know good inhaler technique. That was followed by education of the patient and the caregiver. Forgetfulness was the third most frequently cited barrier, which included forgetting to use the medication at the prescribed time or forgetting to take medication when away from home. The last three barriers were cited once each and included poor communication between caregiver and patient, lack of adequate follow-up by clinicians (too long of a time between visits) and cost of medication.

\section{6 | DISCUSSION}

It is generally acknowledged that knowledge of asthma management is necessary to be an effective self-manager (Allen \& Jones, 1998; Kotses et al., 1995; Meyer, Sternfels, Fagan, Copeland, \& Ford, 2001; van der Palen, Klein, \& Seydel, 1997). Family caregiver scores on the Asthma Self-Management Questionnaire (ASMQ) in the present widely distributed, with a mean score of $6.5( \pm 1.6)$ and a range

instructions, correct use of peak flow metres, inhaler technique, how to prevent asthma flare-ups, reasons for asthma flares and what to do when asthma flares occur and the role of exercise with asthma. Refer to Table 3 for individual items of the ASMQ. 
study were not that much different from scores reported from the initial development and validation study of the instrument (Mancuso et al., 2009). The average caregivers' ASMQ score was $56 \pm 22$ for the present study, while the mean score during the initial development and validation stage was $60 \pm 20$, with a 12-month follow-up score of $68 \pm 18$. In the qualitative portion of the present study, the most commonly mentioned theme that was perceived to be associated with barriers to asthma control and safe medication use by caregivers was knowledge-base for asthma management. This coincides with the relatively poor scores on the asthma self-management questionnaire as well as the inhaler technique questionnaire.

An interesting finding of the current study is that family caregivers had high scores on the health literacy assessment but did not do well on the Asthma Self-Management Questionnaire or Inhaler Technique Questionnaire. This relationship suggests that family caregivers are capable of understanding and learning asthma self-management information and skills. Although not included in this study, employed direct support staff, another group of caregivers often involved in managing a care-recipient's medications, have been found to have health literacy similar to that of family caregivers (Erickson \& LeRoy, 2015). Clinicians and asthma educators, when working with a patient with IDD, should understand that caregivers may provide a significant amount of assistance to patients with IDD. The clinician and educator should determine to what extent the caregiver should be incorporated into asthma self-management training process. The concepts of asthma selfmanagement that seemed to have the greatest deficits identified in this small pilot study include information about asthma flare-ups such as how to prevent flare-ups, reasons for asthma flares and what to do when asthma flares do occur. An area of concern was understanding the role of exercise with asthma. Another concerning area is that of interpreting prescription instructions as well as use of peak flow metres. Lastly, understanding of inhaler technique was lacking not only in the ASMQ, but also in the separate inhaler technique questionnaire. Appropriate inhaler technique is crucial to adequate delivery of medication to the sites of action within the airways of the lungs and symptom control (Giraud \& Roche, 2002). A study to assess the ability of individuals who had IDD and asthma to appropriately use various inhalers found that no person with IDD could correctly us any inhaler device (Davis et al., 2016). A systematic review of studies of patients who do not have IDD found that $46 \%$ to $59 \%$ of patients used inhalers incorrectly (Cochrane, Bala, Downs, Mauskopf, \& Ben-Joseph, 2000). At the same time, studies have demonstrated that patients, including many who have IDD, are able to learn proper technique which leads to improved symptom control (Davis et al., 2016; Newman, Weisz, Talaee, \& Clarke, 1991).

Davis et al. (2015) conducted a qualitative study of support personnel who provide direct care to people with IDD, documenting their experiences with asthma medication management. The primary findings were that support personnel perform many duties, of which medication management is one. Other research confirms that this is true with family caregivers as well (Erickson, Salgado, \& Tan,
2016). Another important finding in the study by Davis et al. was that there appeared to be variation in the level of medication training received by employed support personnel. The support personnel perceived that their role in managing their client's medication is important. The study also found that there may be a lack of decision support available to assist caregivers when performing tasks associated with medication management. These perceptions are similar to those reported by family caregivers in the present study. Of the eleven family caregivers answering the open-ended questions related to barriers to controlling asthma, 36\% $(n=4)$ cited the need for education of the caregiver and patient, along with being able to identify and understand common triggers and asthma symptoms. As far as barriers to using medication safely, $46 \%$ (six of the thirteen family caregivers) were most concerned with knowing and performing inhaler technique correctly, followed again by education of both the patient and caregiver, followed by forgetting to have medication with them when it is time to take it. Less commonly mentioned, but consistent in the themes were issues with communication and coordination of care between patient, clinician and caregiver. These issues are consistent with findings from another qualitative study of caregivers who assist people with IDD managing their medication (Erickson et al., 2016).

Additional findings from this pilot study were that over a third of the patients with IDD did not have desired control of asthma. This is one of the first studies to provide evidence of the level of asthma control in patients with IDD using a validated measure. A number of potential factors measured in this study that may have contributed to lack of control of asthma included nonadherence with controller medications and a modest level of caregiver understanding of asthma management and inhaler technique. The findings of this pilot study are similar to those of patients without IDD. In the general population, as well as in study samples from physician practices, asthma is not well controlled, with population-based studies finding that between $55 \%$ and $59 \%$ of people with asthma are controlled based on assessment of symptoms using standardised instruments (Chapman et al., 2008; Peters et al., 2007; Schatz et al., 2007). In a study using telephone-administered surveys of patients with asthma that also included data from the patients' prescribers, it was determined that $59 \%$ were uncontrolled, $19 \%$ well controlled and $23 \%$ totally controlled. These values are not too dissimilar to those reported in this study. Future research should focus on the patient, treatment and social variables that may be associated with asthma control.

For asthma to be controlled, patients need to be adherent to controller medication (Janson, Wong McGrath, Covington, Cheng, \& Boushey, 2009; Murphy et al., 2012). Studies on medication adherence for people with IDD are not common. The extent of adherence to controller medications by patients in the general population for asthma therapy varies widely based on the method used to assess adherence, treatment type and age group. Studies have documented adherence rates to controller therapy that range from $20 \%$ to $70 \%$ in the general population (Baum \& Creer, 1986; DeSmet, Erickson, \& Kirking, 2006; Gong, Simmons, Clark, \& Tashkin, 1988; Zora, Lutz, \& Tinkelman, 1989). 


\section{1 | Limitations}

The major limitation of this study is the small sample size. This was most likely due to several issues related to the method used to recruit respondents. We did not include an incentive to participate, nor did we reach out to patients other than by mail. In that light, we consider this study to be a pilot study, providing us and other researchers with a glimpse as to what may be important when examining the association between asthma management and asthma control in patients with IDD. It is not possible to generalise the findings of this small study to all caregivers of people with IDD who have asthma, but it does provide a sense of a number of factors that could be more fully explored in future research. Future studies should include not only a larger number of subjects, but also ensure that an adequate number of various types of caregivers are included, which would include family and friends (informal caregivers) and employed support staff, such as direct support professionals staffing group homes, supported apartments or townhouses, or direct-hire personnel assisting an individual within their own home. Strategies to enrol paid carers may be to work directly with the staffing and supports agencies which employ these individuals. Other opportunities to increase the sample size and response rates of all types of caregivers would include offering incentives to participate or to meet potential subjects face to face in clinics or other health-related settings.

Another limitation of this study is that it focused on the caregiver rather than on the patient in regard to asthma management and knowledge. Future work should include the patient with IDD. Evidence suggests that patients with IDD do not receive the same level of health education and health promotion opportunities as the general public (Taggart \& Cousins, 2014). This may be due to the general misconception that people with IDD lack the cognitive ability to understand their complex disease state and therefore lack the ability to self-manage asthma. However, more than half of people with IDD are capable of understanding and responding consistently to interview questions in research studies as well as comprehend basic medical information (Strydom \& Hall, 2001). Identification of problems in medication management among patients with IDD is essential to develop interventions that are tailored to address their needs. Future studies could be developed to test the influence of a targeted or tailored asthma self-management programme designed for people with IDD. This type of programme could be instituted by supports agencies that provide care to people with asthma and IDD. Nationwide, this would potentially impact over two hundred thousand people with asthma and IDD-related conditions.

\section{7 | CONCLUSION}

The results of this pilot study provide initial insight into the level of knowledge and skill of asthma medication management in caregivers of people with IDD. Family caregivers who responded to this survey were found to contribute substantially to asthma medication management for the person they provide care for. Despite adequate levels of health literacy, the family caregivers had generally poor understanding of overall asthma self-management concepts. These trends reveal gaps in knowledge of asthma management and the potential need for additional education and assessment of skills for the caregivers. Improving caregiver and patient knowledge and skills may lead to better asthma control. The present study suggests that conducting well-designed, larger studies that include the patient as well as family and paid carers are warranted.

\section{CONFLICT OF INTEREST}

The authors have no conflicts of interests to report related to the conduct of the study or generation of this manuscript.

\section{ORCID}

Steven R. Erickson iD http://orcid.org/0000-0002-1855-3645

\section{REFERENCES}

Allen, R. M., \& Jones, M. P. (1998). The validity and reliability of an asthma knowledge questionnaire used in the evaluation of a group asthma education self-management program for adults with asthma. Journal of Asthma, 35(7), 537-545. https://doi. org/10.3109/02770909809048956

Baum, D., \& Creer, T. L. (1986). Medication compliance in children with asthma. Journal of Asthma, 23(2), 49-59. https://doi. org/10.3109/02770908609077475

Bazzano, A. T., Zeldin, A. S., Shihady Diab, I. R., Garro, N. M., Allevato, N. A., \& Lehrer, D. (2009). The Healthy Lifestyle Change Program. A pilot of a community-based health promotion intervention for adults with developmental disabilities. American Journal of Preventive Medicine, 37(6S1), S201-S208. https://doi. org/10.1016/j.amepre.2009.08.005

Chapman, K. R., Boulet, L. P., Rea, R. M., \& Franssen, E. (2008). Suboptimal asthma control: Prevalence, detection and consequences in general practice. European Respiratory Journal, 31, 320-325. https://doi. org/10.1183/09031936.00039707

Chew, L. D., Bradley, K. A., \& Boyko, E. J. (2004). Brief questions to identify patients with inadequate health literacy. Family Medicine, 36(8), 588-594.

Cochrane, M. G., Bala, M. V., Downs, K. E., Mauskopf, J., \& Ben-Joseph, R. H. (2000). Inhaled corticosteroids for asthma therapy: patient compliance, devices, and inhalation technique. Chest, 117(2), 542-550. https://doi.org/10.1378/chest.117.2.54

Cohen, J. L., Mann, D. M., Wisnivesky, J. P., Leventhal, H., MusumeciSzabó, T. J., \& Halm, E. A. (2009). Assessing the validity of selfreported medication adherence among inner-city asthmatic adults: The Medication Adherence Report Scale for Asthma. Annals of Allergy Asthma and Immunology, 103(4), 325-331. https://doi.org/10.1016/ S1081-1206(10)60532-7

Davis, S. (2016). Asthma in intellectual disability: Are we managing our patients appropriately? Breathe, 12, 310-317. https://doi. org/10.1183/20734735.014716

Davis, S. R., Durvasula, S., Merhi, D., Young, P. M., Traini, D., \& BosnicAnticevich, S. Z. (2015). The role of direct support professionals in asthma management. Journal of Intellectual \& Develop Disability., 40(4), 342-353. https://doi.org/10.3109/13668250.2015.1041100 
Davis, S., Durvasula, S., Merhi, D., Young, P., Traini, D., \& BosnicAnticevich, S. (2016). The ability of people with intellectual disability to use inhalers-an exploratory mixed methods study. Journal of Asthma, 53(1), 86-93. https://doi.org/10.3109/02770903.2015.106 5423

Desbiens, N. A., \& Mueller-Rizner, N. (2000). How well do surrogates asses the pain of seriously ill patients? Critical Care Medicine, 28(5), 1347-1352. https://doi.org/10.1097/00003246-200005000-00015

DeSmet, B. D., Erickson, S. R., \& Kirking, D. M. (2006). Self-reported adherence in patients with asthma. Annals of Pharmacotherapy, 40(3), 414-420. https://doi.org/10.1345/aph.1G475

Erickson, S. R., Horton, A. M., \& Kirking, D. M. (1998). Assessing metered-dose inhaler technique: Comparison of observation vs. patient self-report. Journal of Asthma, 35(7), 575-583. https://doi. org/10.3109/02770909809048960

Erickson, S. R., \& LeRoy, B. (2015). Health literacy and medication administration performance by caregivers of adults with developmental disabilities. Journal of American Pharmacists Association, 55(2), 169177. https://doi.org/10.1331/JAPhA.2015.14101

Erickson, S. R., Salgado, T. M., \& Tan, X. (2016). Issues in the medication management process in people who have intellectual and developmental disabilities: A qualitative study of the caregivers' perspective. Intellectual and Developmental Disabilities, 54(6), 412-426. https:// doi.org/10.1352/1934-9556-54.6.412

Gale, L., Naqvi, H., \& Russ, L. (2009). Asthma, smoking and BMI in adults with intellectual disabilities: A community-based survey. Journal of Intellectual and Disability Research, 53(9), 787-796. https://doi.org/10 .1111/j.1365-2788.2009.01192

Giraud, V., \& Roche, N. (2002). Misuse of corticosteroid metered-dose inhaler is associated with decreased asthma stability. European Respiratory Journal, 19(2), 246-251. https://doi.org/10.1183/09031 936.02.00218402

Gong,H., Simmons, M.S., Clark, V.A., \& Tashkin, D.P.(1988). Metered-dose inhaler usage in subjects with asthma: Comparison of Nebulizer Chronolog and daily diary recordings. Journal of Allergy and Clinical Immunology, 82(1), 5-10. https://doi.org/10.1016/0091-6749(88)90043-7

Hale, L. A., Trip, H. T., Whitehead, L., \& Conder, J. (2011). Self-management abilities of diabetes in people with an intellectual disability living in New Zealand. Journal of Policy and Practice in Intellectual Disabilities, 8(4), 223-230. https://doi.org/10.1111/j.1741-1130.2011.00314.x

Janson, S. L., Wong McGrath, K., Covington, J. K., Cheng, S. C., \& Boushey, H. A. (2009). Individualized asthma self-management improves medication adherence and markers of asthma control. Journal of Allergy and Clinical Immunology, 123(4), 840-846. https://doi.org/10.1016/j. jaci.2009.01.053.doi.org/10.1016/j.jaci.2009.01.053

Juniper, E. F., Bousquet, J., Abetz, L., Bateman, E. D., \& The GOAL Committee (2006). Identifying 'well-controlled' and 'not wellcontrolled' asthma using the Asthma Control Questionnaire. Respiratory Medicine, 100(4), 616-621. https://doi.org/10.1016/j. rmed.2005.08.012

Juniper, E. F., O'Byrne, P. M., Guyatt, G. H., Ferrie, P. J., \& King, D. R. (1999). Development and validation of a questionnaire to measure asthma control. European Respiratory Journal, 14(4), 902-907. https:// doi.org/10.1034/j.1399-3003.1999.14d29.x

Juniper, E. F., Svensson, K., Mörk, A. C., \& Ståhl, E. (2005). Measurement properties and interpretation of three shortened versions of the asthma control questionnaire. Respiratory Medicine, 99(5), 553-558. https://doi.org/10.1016/j.rmed.2004.10.008

Kerins, G., Petrovic, K., Bruder, M. B., \& Gruman, C. (2008). Medical conditions and medication use in adults with Down syndrome: A descriptive analysis. Downs Syndrome Research and Practice, 12(2), 141-147. https://doi.org/10.3104/research

Kotses, H., Bernstein, I. L., Bernstein, D. I., Reynolds, R. V., Korbee, L., Wigal, J. K., ... Creer, T. L. (1995). A self-management program for adult asthma. Part I: Development and evaluation. Journal of Allergy and Clinical Immunology, 95(2), 529-540. https://doi.org/10.1016/ S0091-6749(95)70315-2

Mancuso, C. A., Sayles, W., \& Allegrante, J. P. (2009). Development and testing of the Asthma Self-Management Questionnaire. Annals of Allergy Asthma and Immunology, 102(4), 294-302. https://doi. org/10.1016/S1081-1206(10), 60334-1

Marks, B., \& Sisirak, J. (2013). Health promotion and people with intellectual disabilities. In L. Taggart, \& W. Cousins (Eds.), Health promotion for people with intellectual and developmental disabilities (pp. 17-30). London, UK: Open University Press, McGraw Hill.

McPherson, C. J., Wilson, K. G., Lobchuk, M. M., \& Brajtman, S. (2008). Family caregivers' assessment of symptoms in patients with advanced cancer: Concordance with patients and factors affecting accuracy. Journal of Pain and Symptom Management, 35(1), 70-82. https://doi.org/10.1016/j.jpainsymman.2007.02.038

Meyer, I. H., Sternfels, P., Fagan, J. K., Copeland, L., \& Ford, J. G. (2001). Characteristics and correlates of asthma knowledge among emergency department users in Harlem. Journal of Asthma, 38(7), 531539. https://doi.org/10.1081/JAS-100107117

Morin, D., Mérineau-Côté, J., Ouellette-Kuntz, H., Tassé, M. J., \& Kerr, M. (2012). Comparison of the prevalence of chronic disease among people with and without intellectual disability. American Journal on Intellectual and Developmental Disability, 117(6), 455-463. https://doi. org/10.1352/1944-7558-117.6.455

Morris, N. S., MacLean, C. D., Chew, L. D., \& Littenberg, B. (2006). The single item literacy screener: Evaluation of a brief instrument to identify limited reading abilitys. BMC Family Practice, 7, 21. https://doi. org/10.1186/1471-2296-7-21

Murphy, A. C., Proeschal, A., Brightling, C. E., Wardlaw, A. J., Pavord, I., Bradding, P., \& Green, R. H. (2012). The relationship between clinical outcomes and medication adherence in difficult-tocontrol asthma. Thorax, 67(8), 751-753. https://doi.org/10.1136/ thoraxjnl-2011-201096

Newman, S. P., Weisz, A. W. B., Talaee, N., \& Clarke, S. W. (1991). Improvement of drug delivery with a breath actuated pressurized aerosol for patients with poor inhaler technique. Thorax, 46(10), 712716. https://doi.org/10.1136/thx.46.10.712

van der Palen, J., Klein, J. J., \& Seydel, E. R. (1997). Are high generalized and asthma-specific self-efficacy predictive of adequate selfmanagement behaviour among adult asthma patients? Patient Education and Counseling, 32, S35-S41. https://doi.org/10.1016/ S0738-3991(97)00094-3

Peters, S. P., Jones, C. A., Haselkorn, T., Mink, D. R., Valacer, D. J., \& Weiss, S. T. (2007). Real-world evaluation of asthma control and treatment (react): Findings from a national web-based survey. Journal of Allergy and Clinical Immunology, 119(6), 1454-1461. https://doi. org/10.1016/j.jaci.2007.03.022

Poort, H., Peters, M. E. W. J., Gielissen, M. F. M., Verhagen, C. A. H. H. V. M., Bleijenberg, G., van der Graaf, W. T. A., ... Knoop, H. (2016). Fatigue in advanced cancer patients: Congruence between patients and their informal caregivers about patients' fatigue severity during cancer treatment with palliative intent and predictors of agreement. Journal of Pain and Symptom Management, 52(3), 336-344. https:// doi.org/10.1016/j.jpainsymman.2016.02.017

Reichard, A., Stolzle, H., \& Fox, M. (2011). Health disparities among adults with physical disabilities or cognitive limitations compared to individuals with no disabilities in the United States. Disability and Health Journal, 4(2), 59-67. https://doi.org/10.1016/j.dhjo.2010.05.003

Schatz, M., Mosen, D. M., Kosinski, M., Vollmer, W. M., Magid, D. J., O'Connor, E., \& Zeigeret, R. S. (2007). Predictors of asthma control in a random sample of asthmatic patients. Journal of Asthma, 44(4), 341-345. https://doi.org/10.1080/02770900701344421

Schieve, L. A., Gonzalez, V., Boulet, S. L., Visser, S. N., Rice, C. E., Van Naarden Braun, K., \& Boyle, C. A. (2012). Concurrent medical conditions and health care use and needs among children with learning 
and behavioral developmental disabilities, National Health Interview Survey, 2006-2010. Research in Developmental Disabilities, 33, 467476. https://doi.org/10.1016/j.ridd.2011.10.008

Strydom, A., \& Hall, I. (2001). Randomized trial of psychotropic medication information leaflets for people with intellectual disability. Journal on Intellectual Disabilities Research, 45(2), 146-151. https:// doi.org/10.1046/j.1365-2788.2001.00329.x

Taggart, L., \& Cousins, W. (2014). Health promotion for people with intellectual disabilities. Maidenhead, UK: Open University Press/McGrawHill Publishers.

van der Palen, J., Klein, J. J., \& Seydel, E. R. (1997). Are high generalized and asthma-specific self-efficacy predictive of adequate selfmanagement behaviour among adult asthma patients? Patient Education and Counseling, 32, S35-S41. https://doi.org/10.1016/ s0738-3991(97)00094-3
Zora, J. A., Lutz, C. N., \& Tinkelman, D. G. (1989). Assessment of compliance in children using inhaled beta adrenergic agonists. Annals of Allergy, 62(5), 406-409.

How to cite this article: Erickson SR, Juncaj S, Buckley C. Family caregivers of people who have intellectual/ developmental disabilities and asthma: Caregiver knowledge of asthma self-management concepts-A pilot study. $\mathrm{Br} J$ Learn Disabil. 2018;46:172-181. https://doi.org/10.1111/bld.12223 